\title{
Grubbs Catalyst 2nd Generation: Synthesis and Activity of Ruthenium-Based Olefin Metathesis Catalysts
}

\section{Key words}

Grubbs catalysts olefin metathesis ruthenium catalysis

ring-closing metathesis

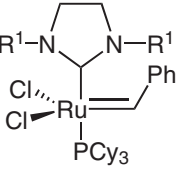

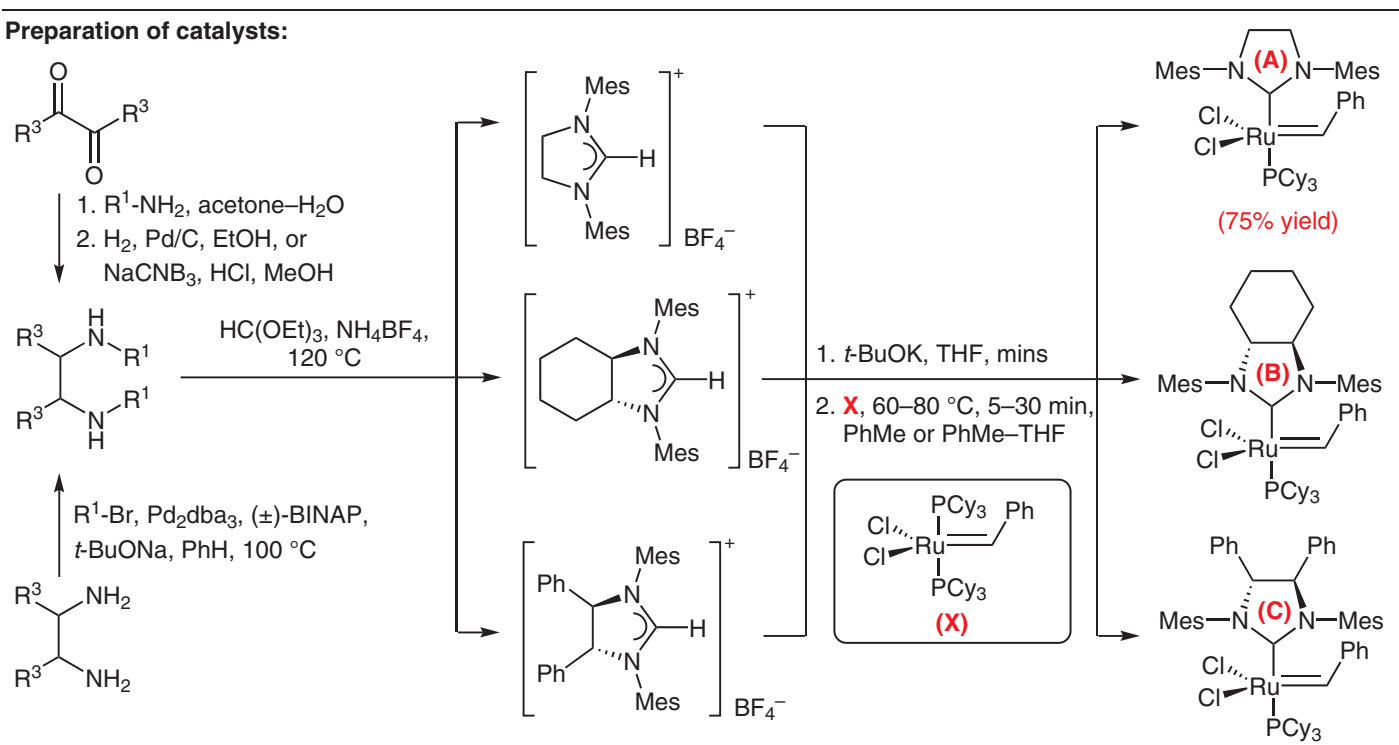

Selected examples of RCM products:

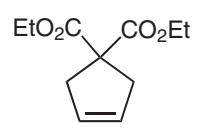

yield $(X)=$ quant

$(A)=$ quant

(B) = quant

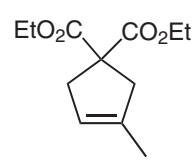

yield $(X)=20 \%$

(A) $=$ quant

(B) = quant

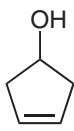

yield $(X)=0 \%$

(A) = quant

(B) $=$ quant

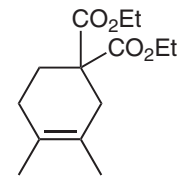

yield $(X)=0 \%$

(A) $=90 \%$

(B) $=87 \%$
Significance: Grubbs and co-workers reported a direct approach towards the preparation of the 4,5dihydroimidazol-2-ylidene-substituted rutheniumbased catalysts. Compared to their predecessor, these 2nd generation catalysts display higher reactivity, better stability, and improved functional group tolerance.
Comment: Conveniently, these 2nd generation catalysts are air- and water-tolerant and can be handled without great loss in activity. Given the increased RCM activities observed with (A) and (B), the authors studied RCM at lower catalyst loadings and found $0.05 \mathrm{~mol} \%$ to be an optimal lower limit in both cases.

Review: O. M. Ogba, N. C. Warner, D. J. O’Leary, R. H. Grubbs Chem. Soc. Rev. 2018, 47, 4510-4544. 